\title{
Kiriş-Kolon Birleşim Bölgesinin Depreme Karşı Çelik Donatılarla Güçlendirilmesi
}

\author{
Hande GÖKDEMİR \\ Tuğrul TANKUT ${ }^{2}$
}

\section{ÖZ}

Çerçeve türü yapıların deprem davranışında kiriş-kolon birleşim bölgelerinin büyük zorlamalar taşıdığı, dolayısıyla bu yapıların deprem güvenliğinde önemli bir rol oynadığı bilinmektedir. Gerilmelerin sağlıklı biçimde taşınabilmesi için birleşim bölgesinde yoğun etriye kullanılması gerekmektedir. $\mathrm{Bu}$ bölgede yönetmelik gereği olan etriyenin yerleştirilmesi oldukça güç olduğundan, bu koşul çoğu zaman yerine getirilememektedir. Bunun sonucu olarak, var olan yapıların büyük çoğunluğunda kiriş-kolon birleşim bölgeleri deprem davranışı açısından son derece yetersiz bir durumdadır. Yeterli kesme donatısı taşımadığı bilinen bir kiriş-kolon birleşim bölgesinde, dışarıdan açılacak eğik deliklere çelik donatı çubukları yerleştirilerek oraya epoksilenmeleri ve her iki ucundan delik dışına kenetlenmeleri sonucunda, birleşim bölgesinde deprem etkisiyle oluşacak eğik asal çekme gerilmelerini güvenilir biçimde taşıyabilecek yeni ve etkili bir düzenleme gerçekleştirilebilir. Bu ilkenin çeşitli durumlarda kolayca uygulanabilir bir birleşim bölgesi güçlendirme tekniği olarak geliştirilmesi, bu araştırmanın ana amacını oluşturmaktadır. ODTÜ Yapı Mekaniği Laboratuvarı'nda deneysel çalışma olağan boyutlu bir çerçevenin bir dış birleşim bölgesini yansıtan T-biçimli ve yaklaşık $2 / 3$ ölçekli deney elemanları üzerinde gerçekleştirilmiştir. İlk dördü referans deneyi olmak üzere; diğerleri birleşim bölgesinde epoksi kullanılarak çapraz şekilde, çelik donatılarla güçlendirilmiş toplam on bir adet deney elemanı test edilmiştir.

Anahtar Kelimeler: Kiriş-kolon birleşim bölgesi, çelik donatı, depreme karşı güçlendirme, epoksi.

\author{
ABSTRACT \\ Seismic Strengthening of Beam-Column Joints with Steel Bars \\ It is well-known that beam-column connections are subjected to high stresses during \\ earthquakes. Therefore, design of these connections play an important role in designing an \\ earthquake resistant structure. Stirrup spacing on beam-column connections should be

\footnotetext{
Not: Bu yazı

- Yayın Kurulu'na 23.11.2015 günü ulaşmıştır.

- 30 Eylül 2017 gününe kadar tartışmaya açıktır.

- DOI: $10.18400 /$ tekderg.307407
} \\ 1 Eskişehir Osmangazi Üniversitesi, İnşaat Mühendisliği Bölümü, Eskişehir - handeg@ogu.edu.tr \\ 2 Orta Doğu Teknik Üniversitesi, İnşaat Mühendisliği Bölümü, Ankara - ttankut@metu.edu.tr
}


Kiriş-Kolon Birleşim Bölgesinin Depreme Karşı Çelik Donatılarla Güçlendirilmesi

smaller in order allow for safety in carrying the stresses. Since the placement of ties required by the code in this region is rather difficult, this condition is fulfilled with difficulty. As a result of this difficulty, beam-column joints are in a very unfavorable state in terms of seismic behavior. In a beam-column connection which has no sufficient shear reinforcement, it is thought that additional reinforcement which is arranged by placing steel bars into inclined holes drilled from outside and anchored by epoxy can carry principal tensile stresses on beam-column connections. This experimental study was carried out at the METU Structural Mechanics Laboratory by using T-shaped test specimens reflecting an exterior joint region of a frame having normal dimensions to a scale of $2 / 3$. In total, eleven elements were tested, four of which are reference specimens, while the others are strengthened at their joint regions with diagonal steel bars.

Keywords: Beam-column joints, steel bars, seismic strengthening, epoxy.

\section{GíRIŞ}

Yapılarda çerçeve elemanlarının deprem davranışı açısından bireysel olarak güçlendirilmesinde "Eleman Güçlendirme Teknikleri" kategorisinde yer alan çeşitli teknikler uygulanmaktadır. "Sistem Davranışı İyileştirme Teknikleri” uygulamalarındaki amaç ise çerçevelerden oluşan yetersiz yanal yük taşıyıcı sistemin yerine, rijit düşey elemanlardan oluşan yeni bir yanal yük taşıyıcı sistem oluşturmaktır. Bunun için ya deprem yüklerinin büyük bölümünü alarak mevcut yapıyı rahatlatan yeni elemanlar yerleştirilir ya da taban yalıtımı sistemleri ve sönümlendiriciler kullanılarak deprem etkilerinin yapıya aktarılması engellenmeye çalışı1ır.

Birinci kategoride yer alan eleman güçlendirme teknikleri arasında, kolonların, kirişlerin, perdelerin, döşemelerin ve temellerin güçlendirilmesine yönelik çeşitli teknikler bulunmasına karşın, kiriş-kolon birleşimlerinin deprem için güçlendirilmesi amacıyla kullanılabilecek çok elverişli, ekonomik, etkin ve pratik bir güçlendirme tekniğindeki gelişmeler yeterli değildir.

Oysa, çerçeve türü yapıların deprem yüklerine karşı davranışında, kiriş-kolon birleşim bölgelerinin büyük zorlamalara maruz kaldığı bilinmektedir. Dolayısıyla bu bölgelerin güçlendirilmesinin önemi deprem güvenliği açısından ortaya çıkmaktadır.

Deprem kuvvetleri, birleşim bölgesinde büyük kesme kuvvetleri oluşturmakta, bunlardan kaynaklanan eğik asal çekme gerilmeleri de çatlamalara neden olmakta ve giderek birleşim bölgesindeki betonun dağılmasına yol açmaktadır. Bu gerilmelerin sağlıklı biçimde taşınabilmesi için birleşim bölgesinde yoğun etriye kullanılması gerekmektedir. Nitekim, yürürlükteki deprem yönetmeliği de; kolon ucundaki etriye sıklaştırma bölgesinde kullanılan yoğun etriyenin bir bölümünün, birleşim bölgesi içinde de sürdürülmesini önermektedir. Ancak, bu bölgede yönetmelik gereği olan etriyenin yerleştirilmesi oldukça güç olduğundan, yönetmelik gereği, genellikle çoğu zaman yerine getirilememekte ve birleşim bölgesine çoğu zaman hiç etriye konulmamaktadır. Bunun sonucu olarak, var olan yapıların büyük çoğunluğunda kiriş-kolon birleşim bölgeleri deprem davranışı açısından son derece yetersiz bir durumdadır.

Özellikle yanal rijitlik yetersizliğinin çok yaygın olması nedeniyle, Türkiye'de, "Eleman Güçlendirme" yaklaşımı yalnız başına uygulandığında çoğunlukla başarılı, verimli ve 
ekonomik olamamakta; bu yüzden "Sistem Davranışı İyileştirme" yaklaşımını temel alarak var olan kusurlu yapı elemanlarını deprem etkilerinden kurtararak yeterli duruma getirmeyi amaçlayan ve bu işlem gerçekleştirildikten sonra eğer hala kalmışsa kalan sınırlı sayıda yetersiz çerçeve elemanını güçlendirmekle yetinen bir güçlendirme stratejisi genellikle benimsenmektedir. $\mathrm{Bu}$ strateji izlendiğinde diğer yetersiz elemanlar gibi kiriş-kolon birleşimlerinin yetersizliği de önemini kaybetmekte ve kiriş-kolon birleşim bölgeleri yetersiz olan yapılar da çoğu zaman yeterli deprem güvenliğine kavuşturulabilmektedir.

Bununla birlikte Türkiye'de çok yaygın değilse bile, dünyanın birçok ülkesinde, yapıların depreme karşı güçlendirilmesinde "eleman güçlendirme" yaklaşımı yaygın olarak kullanılmaktadır. Dolayısıyla etkili, elverişli ve ekonomik bir birleşim bölgesi güçlendirme tekniği geliştirilmesine gereksinim bulunmaktadır.

Depremlerde yapılardaki birleşim bölgesinin taşıma kapasitesini arttırmak ve ani göçmeyi engellemek için kolay, ekonomik ve etkin yöntemler geliştirmek gerekmektedir. Güçlendirmenin binalar boşaltılmadan ve bina sakinlerine rahatsızlık verilmeden hızlı bir şekilde yapılması da önemli olmaktadır. Birleşim bölgesi kırılmasından kaynaklanan göçmeleri önlemek için temel ilke, birleşim bölgelerinde önemli bir hasar olmaksızın, kirişte mafsal oluşmasını sağlamaktır. Bu durum sağlandığı taktirde sünek bir davranış biçimi gerçekleşmiş olur.

Antonopoulus vd. [1], Ghobarah vd. [2], Prota vd. [3] kiriş-kolon birleşim bölgelerinde; CFRP (karbon fiber güçlendirmeli polimerler) ve GFRP (cam fiber güçlendirmeli polimerler) tabakaların kiriş-kolon birleşim bölgesine dıştan sarılmasıyla güçlendirme çalışmaları yapmışlardır. Bu tür birleşim bölgesi güçlendirme çabaları, gerçek anlamda birleşim güçlendirmesi olmadıkları gibi, uygulanabilir olmaktan da uzaktırlar. Gerçekte, kiriş ve kolon uçlarını sargılamak anlamına gelen bu yaklaşımlar laboratuvardaki test elemanlarına kolayca uygulanabilirse de, döşeme plakları da içeren üç boyutlu çerçevelerin birleşim bölgelerine uygulanmaları pratik değildir. Taşlıgedik A.Ş. [4] CFRP ruloların bindirme boyu davranışı ile ilgili deneyler yapmıştır. Bu çalışma kapsamında; yeterli kesme donatısı taşımadığı bilinen bir kiriş-kolon birleşim bölgesinde, dışarıdan açılacak eğik deliklere çelik donatı çubukları yerleştirilerek oraya epoksilenmeleri ve her iki ucundan delik dışına kenetlenmeleri sonucunda, birleşim bölgesinde deprem etkisiyle oluşacak eğik asal çekme gerilmelerini güvenilir biçimde taşıyabilecek yeni ve etkili bir düzenleme gerçekleştirilebilir.

Gökdemir H. [5] çelik donatıların zayıf kiriş-kolon birleşim bölgesine çapraz olarak yerleştirilmesiyle gerçekleşen güçlendirme deneylerini ilk kez yapmıştır. Mevcut binaların kiriş-kolon birleşim bölgelerinde çok donatı bulunması halinde; çelik donatıların bir uçtan diğer uca geçmesi mümkün olamamaktadır. Bu durumda; karşılıklı iki taraftan çapraz ve çelik donatıların yerleştirilmesiyle bindirmeli ek içeren çalışmalar yapılmıştır. Malzemenin cinsi, miktarı, ankrajlanma şekli ve bindirme boyu araştırılan başlıca parametrelerdir. Hedeflenen amaç depremlerde en çok hasar gören betonarme yapıların kiriş-kolon birleşim bölgelerine kesme donatısı niteliğinde çelik donatı çubukları yerleştirerek, birleşimin güçlendirilmesini sağlayan yeni ve pratik bir teknik geliştirmektir. $\mathrm{Bu}$ yöntemin uygulanmasıyla kiriş-kolon birleşim bölgelerinin kesme kuvvetlerine karşı dayanımı arttırılacak, kirişte mafsal oluşması sağlanacak ve daha sünek bir davranış elde edilmiş olacaktır. 


\section{DENEYSEL ÇALIŞMA}

\subsection{Deney Elemanları}

Kiriş-kolon birleşim bölgesine çapraz olarak yerleştirilen nervürlü donatılarla yapılan güçlendirme çalışmalarında dış kiriş-kolon birleşim bölgesi seçilmesinde, donatı oranlarının belirlenmesinde, deney elemanlarının boyutlarının belirlenmesinde ve deney düzeninin tasarımında, daha önce Kanada'da yapılmış olan bir çalışmadan Seçkin M. [6] kapsamlı biçimde yararlanılmıştır. Hipotetik prototip çerçeve göz önüne alınmış ve yapı bölgesi izole edilerek deney elemanları oluşturulmuştur.

Olağan boyutlu bir çerçevede bir dış birleşim bölgesini oluşturan ve kolonlar ile kirişin açıklıları ortasında birer mafsal (moment sıfır noktası) bulunduğu varsayımı ile tanımlanan kolon ile kirişten oluşan ve kolon uç noktalarında mafsallanmış olan ve laboratuvar olanakları, yükleme ve ölçüm araçlarının kapasiteleri göz önünde bulundurularak deney elemanları için 2/3 ölçek kullanılması tasarlanmıştır.

Daha sonra, deney koşullarını basitleştirmek amacıyla, kirişin boyu kısaltılmıştır. Bu durumda; kesme daha kritik olacağından, yapılacak bir güçlendirmenin genel durumda daha başarılı olacağı düşünülmüştür.

Deney elemanları TS 500 ve Türk Deprem Yönetmeliği’ne göre hazırlanmıştır. B deney dizilerinde birleşim bölgesinde etriye kullanılmamıştır. Deney elemanlarının boyutları ve donatı düzeni Şekil 4'te gösterilmiştir.

Deney elemanlarının beton sınıfı C20'dir. Deney günü kırılan silindir numunelerin test sonuçları Tablo 1'de gösterilmiştir. Ve S420 donatıları kullanılarak deney elemanları tasarlanmış ve deney elemanlarının donatı özellikleri Tablo 2'de gösterilmiş̧ir.

Çelik donatıların beton içine ankrajında epoksi kullanılmıştır. Epoksi, MBRACE Adesivo Saturant A \& Saturant B'nin 1/3 oranında karıştırılmasıyla elde edilmiş ve uygulanmıştır.

Tablo 1. Deney günü kirllan numunelerin test sonuçları

\begin{tabular}{|c|c|}
\hline Deney elemani & $\mathbf{f}_{\mathbf{c m}}$ (MPa) \\
\hline $\mathrm{PR}$ & 19.7 \\
\hline $\mathrm{RL}$ & 20.8 \\
\hline $\mathrm{RC}$ & 21.5 \\
\hline $\mathrm{RU}$ & 21.4 \\
\hline $\mathrm{S} 20 \mathrm{~B}$ & 21.3 \\
\hline $\mathrm{S} 20 \mathrm{~W}$ & 22.2 \\
\hline $\mathrm{S} 20$ & 20.6 \\
\hline $\mathrm{S} 16 \mathrm{~B}$ & 20.1 \\
\hline $\mathrm{S} 20 \mathrm{BL}$ & 21.4 \\
\hline $\mathrm{S} 16 \mathrm{BL}$ & 21.3 \\
\hline $\mathrm{S} 14 \mathrm{BL}$ & 20.9 \\
\hline
\end{tabular}


Tablo 2. Deney elemanları donatı özellikleri

\begin{tabular}{|c|c|c|c|c|c|}
\hline Donatı konumu & Sayı & $\begin{array}{c}\text { Çapı } \\
\phi(\mathbf{m m})\end{array}$ & Özellik & $\begin{array}{c}\text { Akma } \\
\text { Dayanımı } \\
\mathbf{f}_{\mathbf{y}}(\mathbf{M P a})\end{array}$ & $\begin{array}{c}\text { Kopma } \\
\text { Dayanımı } \\
\mathbf{f}_{\mathbf{u}} \mathbf{( M P a )}\end{array}$ \\
\hline Kiriş boyuna & 5 & 20 & Nervürlü & 536 & 623 \\
\hline Kolon boyuna & 4 & 20 & Nervürlü & 536 & 623 \\
\hline Çapraz & $4-8$ & $16-20$ & Nervürlü & $430-536$ & $667-623$ \\
\hline Etriye & $32-36$ & 8 & Düz & 360 & 490 \\
\hline
\end{tabular}

Deprem yükünün çerçeveye soldan sağa etkimesi halinde; yatay yükler altında zorlanan kiriş-kolon birleşim bölgesine birleşen elemanlardan yani kolon ve kirişten aktarılan kuvvet çiftleri Şekil 1'de görülmektedir. Buradan, birleşim bölgesinin büyük zorlamalara maruz kaldığı anlaşılmaktadır.

Kirişin üst tarafında oluşan kuvvetler birbirleriyle aynı yöndedir. Alt kısmında oluşan kuvvetler de birbirleriyle aynı yönde fakat üstteki kuvvetlere göre ters yönde etki etmektedirler.

Kolonda da soldaki kuvvetler birbirleriyle aynı yönde, sağdaki kuvvetler de birbirleriyle aynı yönde fakat soldakine göre ters yönde etkimektedirler. Deprem yükleri; tersiniryinelenir olduğundan, deprem yükünün çerçeveye sağdan sola etkimesi halinde, birleşimde oluşan tüm kuvvetlerin yönü, ters yönde değişmektedir.

Kiriş-kolon birleşim bölgesinin ortasından bir eleman ele alındığında; bu elemanda oluşan kayma gerilmeleri Şekil 2'de, asal çekme gerilmeleri de Şekil 3'te gösterilmiştir.

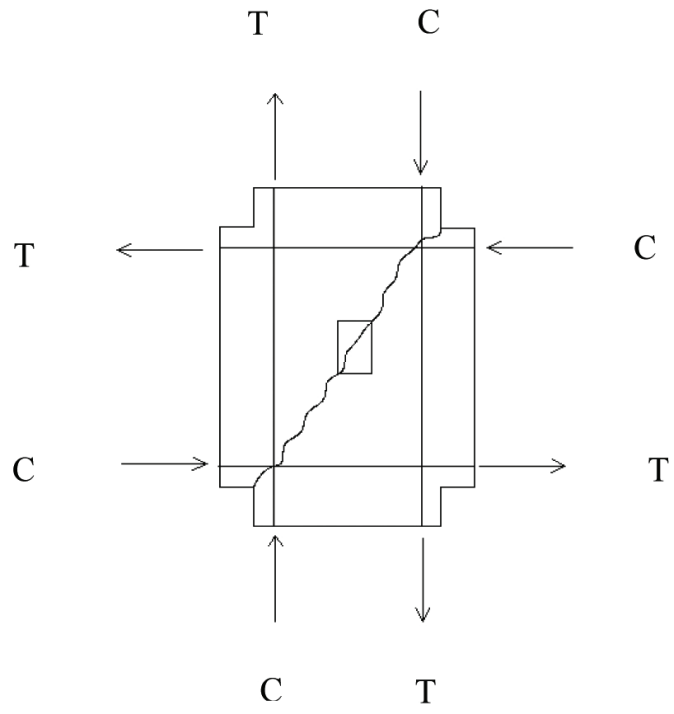

Şekil 1. Birleşim bölgesine birleşen elemanlardan aktarllan kuvvet çiftleri 
Kiriş-Kolon Birleşim Bölgesinin Depreme Karşı Çelik Donatılarla Güçlendirilmesi

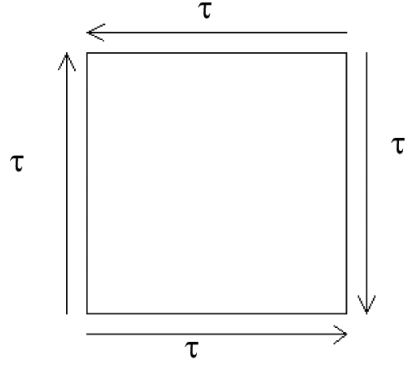

Şekil 2. Kayma gerilmeleri

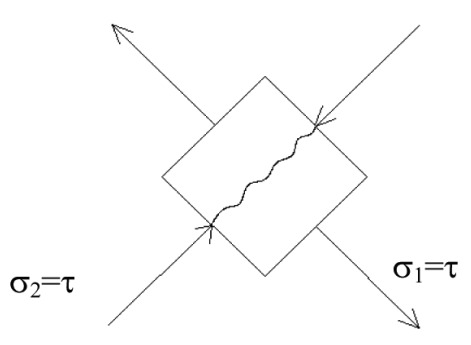

Şekil 3. Asal çekme gerilmeleri

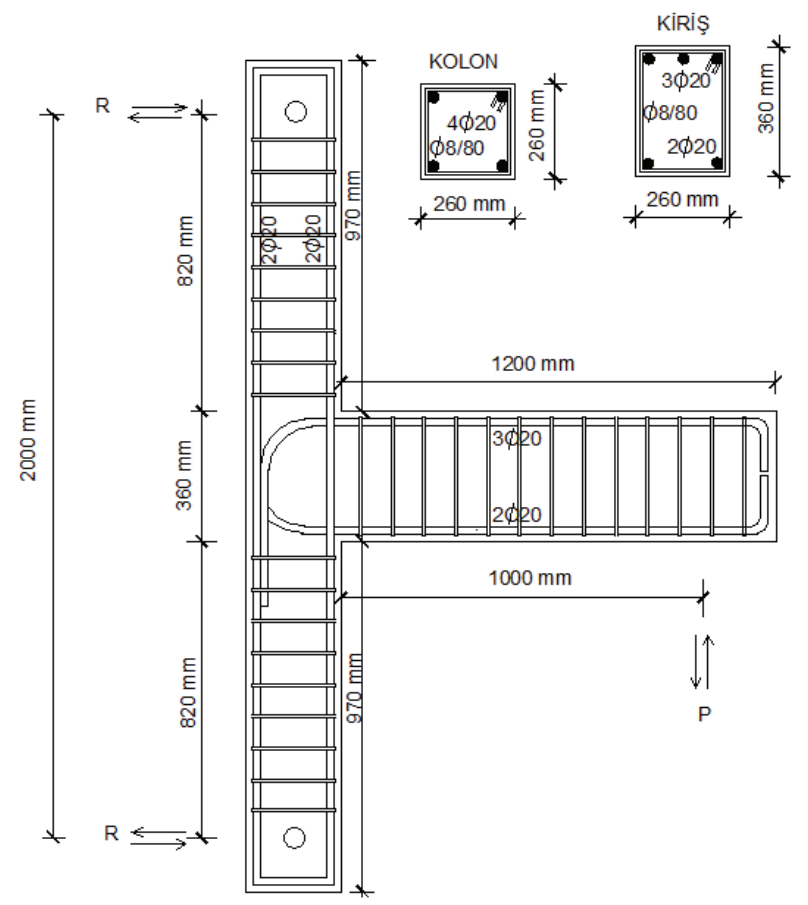

Şekil 4. Deney elemanlarinın boyutları ve donatı düzeni (Birleşim bölgesi donatısı gösterilmemiştir)

Kiriş-kolon birleşim bölgesindeki çapraz donatılar kaynaklı ya da somunlu olarak ankrajlanmıştır. Somunlu ankrajlama Şekil 5'te gösterilmiştir. 


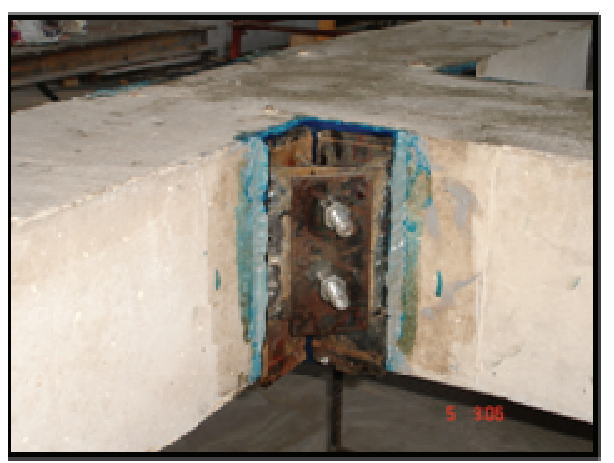

Şekil 5. Çelik donatı uçlarının somunla tutturulması

S20BL, S16BL, S14BL deney elemanlarında ise donatılar birleşim bölgesine iki taraftan çapraz ve bindirmeli olarak yerleştirilmiştir. Bindirme boyu $400 \mathrm{~mm}$ (20 donatı çapı) ve bindirmeli donatılar arası mesafe $20 \mathrm{~mm}$ 'dir.

Deney programı iki deney dizisinden meydana gelmiştir:

(i) Referans dizileri,

(ii) Çelik donatılarla güçlendirme.

Tüm deney dizileri ve donatı özellikleri Tablo 3 ’te gösterilmiştir. Tabloda da görüldüğü gibi aşağıdaki parametrelerin incelenmesi amaçlanmış ve deney serileri buna göre düzenlenmiştir.

- Kiriş-kolon birleşim bölgesinin davranış ve dayanımdaki etkisini incelemek için birleşime yerleştirilen etriye miktarının değişimi

- Çapraz çelik donatılarla birleşim bölgesini güçlendirme etkisi

- Nervürlü donatıların uçlarının ankrajlanma şeklinin etkisi; somunlu, kaynaklı, serbest

- Nervürlü donatı miktarının etkisi

- Nervürlü donatıların yerleştirilme şeklinin etkisi; bindirmeli veya direkt

\subsection{Deney Düzeneği}

Mesnetleme ve yükleme düzeneği Şekil 7'de gösterilmiştir.

Kolon üstten ve alttan güçlü duvara mafsallanmıştır. Kolonun altına ve yük hücresinin üstüne yerleştirilen plakalara delikler açılmış, uçları kilitlenmiş halatlarla plakalar sıkıştııılarak, plakalar arasına yerleştirilmiş olan deney elemanına eksenel kuvvet uygulanmıştır.

Kolon eksenel yük taşıma kapasitesinin yaklaşı $\% 20$ 'si, kolonun üstünden eksenel yük olarak uygulanmış ve bu yük deneyin sonuna kadar sabit tutulmuştur. 
Kiriş ucundan uygulanan tersinir-yinelenir yük çift tesirli hidrolik kriko, yük hücresi ve mafsallarla üstten kirişe alttan da güçlü döşemeye tutturularak sağlanmıştır.

Ölçüm aletlerinin yerleşim ve adlandırma düzeni Şekil 8'de gösterilmiştir. Yük-kiriş ucu deplasman grafiğinin yanında birleşim bölgesinde kesme deplasman ve moment eğrilik grafikleri çizilmiştir.

Tablo 3. Deney dizileri ve eleman özellikleri

\begin{tabular}{|c|c|c|c|c|}
\hline Diziler & $\begin{array}{c}\text { Deney } \\
\text { Elemanları }\end{array}$ & $\begin{array}{c}\text { Birleşim Bölgesi } \\
\text { Donatıları }\end{array}$ & $\begin{array}{l}\text { Birleşim Bölgesi } \\
\text { Güçlendirme }\end{array}$ & Açıklama/Ankraj \\
\hline \multirow{4}{*}{$\begin{array}{c}\text { A } \\
\text { Referans }\end{array}$} & PR & - & - & Ön deney \\
\hline & RL & - & - & $\begin{array}{l}\text { Referans, } \\
\text { alt düzey }\end{array}$ \\
\hline & $\mathrm{RC}$ & Etriye, $\phi 8 / 80 \mathrm{~mm}$ & - & $\begin{array}{c}\text { Referans, } \\
\text { yönetmelik }\end{array}$ \\
\hline & RU & Etriye, $\phi 8 / 50 \mathrm{~mm}$ & - & $\begin{array}{l}\text { Referans, } \\
\text { üst düzey }\end{array}$ \\
\hline \multirow{7}{*}{$\begin{array}{c}\text { B } \\
\text { Çelik } \\
\text { Donatılı } \\
\text { Güçlendirme }\end{array}$} & S20B & - & $2 \times 2 \phi 20$ diyag. & Somunlu + epoksi \\
\hline & S20W & - & $2 \times 2 \phi 20$ diyag. & Kaynakl $1+$ epoksi \\
\hline & S20 & - & $2 \times 2 \phi 20$ diyag. & $\begin{array}{l}\text { Serbest, sadece } \\
\text { epoksi }\end{array}$ \\
\hline & S16B & - & $2 \times 2 \phi 16$ diyag. & Somunlu + epoksi \\
\hline & S20BL & - & $2 \times 2 \phi 20$ diyag & $\begin{array}{c}\text { Somunlu + epoksi } \\
\text { bindirmeli }\end{array}$ \\
\hline & S16BL & - & $2 \times 2 \phi 16$ diyag. & $\begin{array}{c}\text { Somunlu + epoksi } \\
\text { bindirmeli }\end{array}$ \\
\hline & S14BL & - & $2 \times 1 \phi 20$ diyag. & $\begin{array}{c}\text { Somunlu + epoksi } \\
\text { bindirmeli }\end{array}$ \\
\hline
\end{tabular}

\subsection{Deney Sonuçları}

Gökdemir H. [5] çalışmasındaki deney verileri kullanılarak çeşitli grafikler hazırlanmış ve bu grafikler dayanım, dayanımdaki azalma, süneklik, enerji tüketimi, rijitlik, rijitlik azalması ile ilgili olarak çizilmiştir.

Deney sonuçlarıyla ilgili detaylı bilgi bulunabilir. Kısa özet Tablo 4'te verilmiştir.

Güçlendirme çalışmalarında, birleşim bölgesinde çok önemli bir hasar olmadan kiriş eğilme donatılarının akması yani kirişte mafsallaşma oluşması amaçlanmıştır. Güçlendirmenin başarısı bu ölçüte göre değerlendirilmiştir. Tablo 4'te verilen değerler bu anlayışla yorumlanmaktadır. 
$\mathrm{Bu}$ tabloda dört tür performansa göre değerlendirme yapılmaktadır. Bunlar: kapasite, süneklik, başlangıç rijitliği ve kiriş eğilme donatısının akıp akmamasıdır. Genel başarı bu dört kriter temel alınarak değerlendirilmiştir.

Kapasite oranı; en büyük yükün, kiriş eğilme donatısının akma yüküne oranı olarak tanımlanmıştır. $\left(\mathrm{P}_{\text {maks }} / \mathrm{P}_{\mathrm{y}}\right)$

Süneklik oranı ise genelde yük-kiriş ucu deplasman grafiklerindeki en büyük yükün \%85'ine karşılık gelen deplasmanın, akma anındaki deplasmana oranı olarak gösterilmektedir. Fakat yapılan deneylerde en büyük yükün aniden düşmesi ve eğimin değişmesi nedeniyle, bu yüke karşıllı gelen deplasman değerleri grafiklerden tam olarak belirlenememiştir. Bundan dolayı en büyük yükteki ani düşme nedeniyle bu yükün $\% 85$ yerine, yaklaşık \%60'ına karşılık gelen deplasman değerleri $\left(\delta_{60}\right)$ gözlenmiş ve Tablo 4'ün yedinci sütununda $\left(\delta_{60} / \delta_{\mathrm{y}}\right)$ oranı gösterilmiş̧tir. Bu değerin, gerçek sünekliği yansıtmasa da bir karşılaştırma oranı olarak anlamlı olduğu düşünülmüsştür.

Eğilme rijitliği, moment-eğrilik ilişkisinin eğimidir. İdeal malzeme davranışına dayalı elastisite teorisinde $\mathrm{K}=\mathrm{M} / \mathrm{EI}$ bağıntısı geçerli olduğundan, eğilme rijitliği EI olarak tanımlanır. Oysa davranışı ne doğrusal ne de elastik olmayan betonarme için bu basitleştirme geçerli değildir gerçek M-K ilişkisinin eğimi göz önüne alınmalıdır.

Ancak, bu çalışmada yük-deplasman eğrisinin çıkış bölgesi eğimi, rijitliğin yaklaşık bir göstergesi olarak kullanılmıştır. Bu gösterge mutlak değerce doğru değilse de, tüm elemanlara uygulandığından bir karşılaştırma aracı olarak yeterlidir.

Kiriş-kolon birleşimindeki kiriş donatılarına yerleştirilen birim deformasyon ölçerlerden alınan okumalardan, kirişlerdeki eğilme donatılarının akıp akmadığ 1 gözlenmiştir. Bazı deney elemanlarında ise kirişle kolonun birleştiği yüzeyde oluşan eğilme çatlaklarının büyüklüğü burada akma olduğunu doğrulamaktadır. Deney sırasındaki birleşim bölgesi hasarı ise Şekil 6'da görülmektedir.

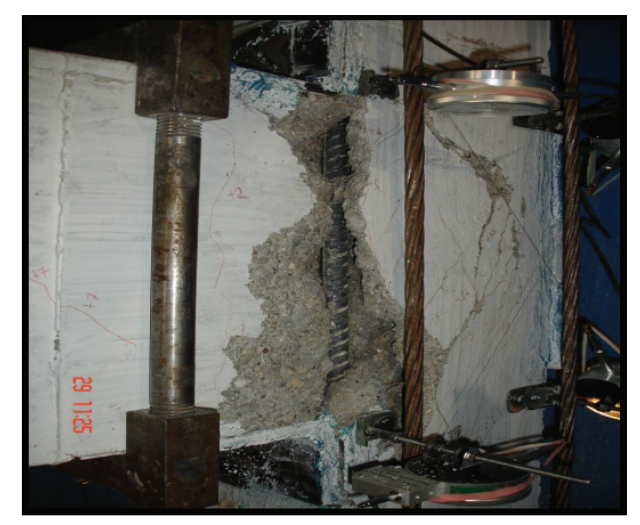

Şekil 6. Deney sırasındaki birleşim bölgesi hasarı (S20BL) 
Kiriş-Kolon Birleşim Bölgesinin Depreme Karşı Çelik Donatılarla Güçlendirilmesi
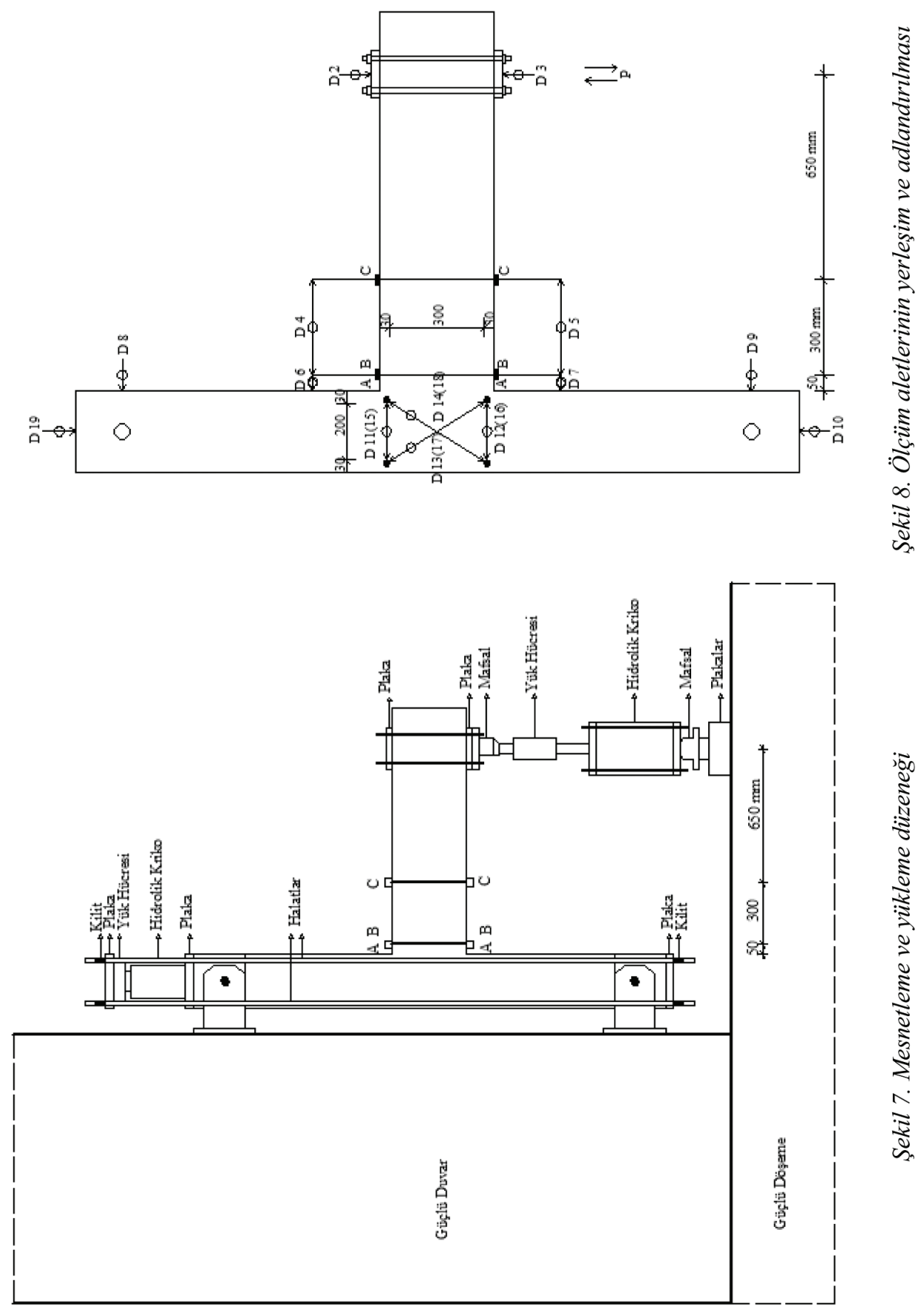
Hande GÖKDEMIR, Tuğrul TANKUT

\begin{tabular}{|c|c|c|c|c|c|c|c|c|c|c|}
\hline 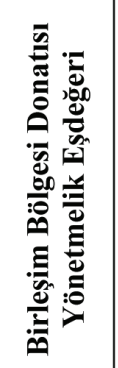 & 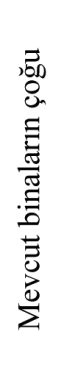 & 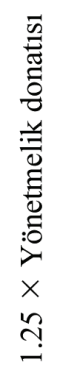 & 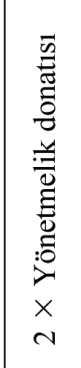 & 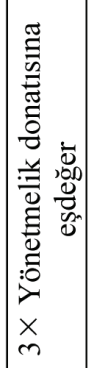 & 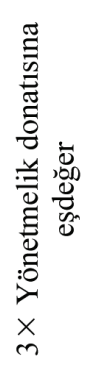 & 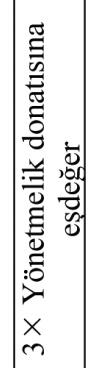 & 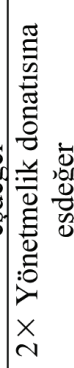 & 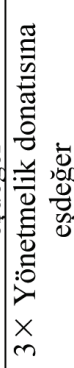 & 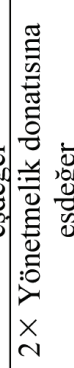 & 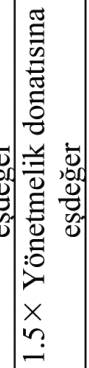 \\
\hline 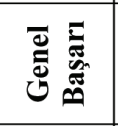 & 岸 & 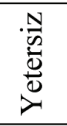 & 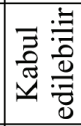 & 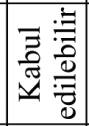 & 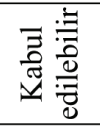 & 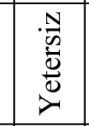 & 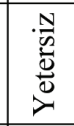 & 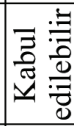 & 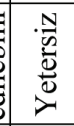 & 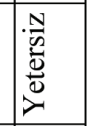 \\
\hline 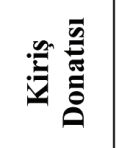 & $\begin{array}{l}\bar{E} \\
\frac{\tilde{E}}{Z} \\
\end{array}$ & 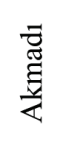 & $\frac{E}{4}$ & $\frac{\bar{y}}{4}$ & 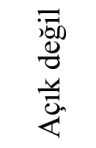 & 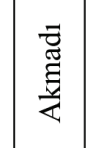 & 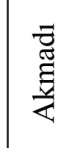 & $\bar{z}$ & $\begin{array}{l}\overline{\tilde{z}} \\
\bar{\Xi} \\
\end{array}$ & 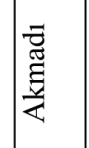 \\
\hline 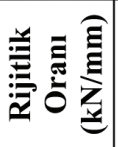 & $\begin{array}{c}\infty \\
i\end{array}$ & $\begin{array}{c}\infty \\
l\end{array}$ & $\frac{2}{2}$ & $\frac{0}{2}$ & $\frac{2}{2}$ & $\frac{0}{i}$ & $\frac{\circ}{2}$ & $\frac{9}{2}$ & $\frac{0}{2}$ & $\frac{0}{2}$ \\
\hline 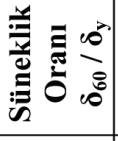 & $\underset{i}{i}$ & $\stackrel{+}{i}$ & $\underset{+}{i}$ & $\stackrel{n}{i}$ & 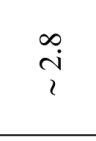 & $\stackrel{m}{i}$ & $\hat{i}$ & $\hat{i}$ & $\stackrel{n}{i}$ & $\begin{array}{l}0 \\
\dot{m} \\
i\end{array}$ \\
\hline$\infty^{2} \widehat{\widehat{E}}$ & $\frac{7}{2}$ & $\underset{\text { ลี }}{2}$ & $\underset{\imath}{2}$ & $\underset{\imath}{2}$ & $\underset{\imath}{2}$ & $\frac{1}{2}$ & $\underset{i}{\stackrel{J}{2}}$ & $\underset{i}{i}$ & $\underset{\text { I }}{\text { ? }}$ & $\frac{1}{2}$ \\
\hline 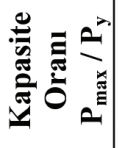 & 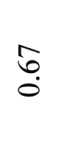 & $\stackrel{a}{0}$ & $\stackrel{\sigma}{\sigma}$ & $\stackrel{\infty}{\circ}$ & $\bar{g}$ & $\stackrel{R}{0}$ & $\begin{array}{l}\infty \\
\infty \\
0\end{array}$ & $\hat{o}$ & $\begin{array}{l}\infty \\
\infty \\
0\end{array}$ & $\stackrel{\infty}{\infty}$ \\
\hline 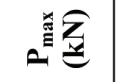 & t & $\Xi$ & 寻 & $\hat{n}$ & $\widehat{\Xi}$ & $\stackrel{\infty}{\circ}$ & $\cong$ & $\stackrel{0}{\stackrel{\sim}{\sim}}$ & $\widetilde{\Xi}$ & $\stackrel{\circ}{=}$ \\
\hline 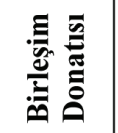 & ' & $\begin{array}{l}\text { ह } \\
\stackrel{\Xi}{\infty} \\
\infty \\
\infty \\
\Theta\end{array}$ & 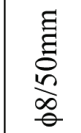 & 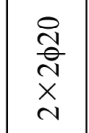 & $\begin{array}{l}\text { तิ } \\
\stackrel{\tilde{N}}{x} \\
\stackrel{\sim}{N}\end{array}$ & 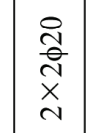 & $\begin{array}{l}\frac{0}{a} \\
\stackrel{\tilde{N}}{x} \\
\stackrel{\sim}{N}\end{array}$ & $\begin{array}{l}\text { ते } \\
\text { ते } \\
\text { × } \\
\text { N }\end{array}$ & $\begin{array}{l}0 \\
\stackrel{0}{a} \\
\stackrel{\tilde{N}}{\mathbf{n}} \\
\text { v. }\end{array}$ & $\begin{array}{l}\text { a } \\
\frac{\tilde{a}}{x} \\
\text { v }\end{array}$ \\
\hline 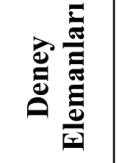 & $\vec{\imath}$ & $\underset{\simeq}{ }$ & $\vec{x}$ & $\begin{array}{l}\text { 额 } \\
\text { क }\end{array}$ & $\begin{array}{l}\text { 令 } \\
\text { ñ }\end{array}$ & జ్ & $\begin{array}{l}\frac{n}{0} \\
\sim\end{array}$ & $\begin{array}{l}\vec{m} \\
\text { 空 } \\
\text { ñ }\end{array}$ & $\frac{\overrightarrow{0}}{\overrightarrow{0}}$ & $\frac{\vec{m}}{\vec{w}}$ \\
\hline$\frac{\bar{d}}{\frac{\pi}{\pi}}$ & & «龍 & & & & & & & & \\
\hline
\end{tabular}




\section{TARTIŞMA}

Zarf eğrileri, yük-deplasman grafiğindeki kiriş ucundan verilen tersinir-yinelenir yük durumu için tüm deneylerde iki farklı durumdaki deney dizileri birleştirilerek Şekil 9 ve 10 'da sunulmuştur. Zarf eğrilerinde pozitif yük ve deplasman değerleri kiriş ucundaki yükün yukarıdan aşağı verildiğini ve kiriş ucu deplasmanın aşağı doğru olduğunu, negatif yük ve deplasman değerleri ise; kiriş ucu yükün aşağıdan yukarıya verildiğini ve kiriş ucu deplasmanın yukarı doğru olduğunu göstermektedir. Şekil 9 referans deneylerini içerir (Deney dizileri A); Şekil 10 çelik donatılarla güçlendirilmiş deney elemanları eğrilerini göstermektedir (Deney dizileri B). Eğrilerden son ikisi de referans deneylerinden alt ve üst sınır durumları içermektedir.

$\mathrm{Bu}$ grafikler üzerinde dikkatli ve hassas olarak yapılan bazı ilginç gözlemler Tablo 4'te verilen performans göstergeleri ile birlikte özetlenmiş ve kısaca aşağıdaki iki alt başlıkta ele alınmıştır.

\subsection{Dizi A: Referans Deneyleri}

- Birleşim bölgesinde etriye bulunmayan (RL) deney elemanı beklendiği gibi yetersiz olmuştur.

- Birleşim bölgesinde etriye arttıkça, davranış ve dayanım doğal olarak iyileşmiştir.

- Yönetmeliğin öngördüğünden \% 25 daha fazla birleşim donatısı (RC), yetersiz kalmıştır. Ancak yönetmelik donatısının iki katı kadar etriye konulduğunda, istenen davranış elde edilebilmiştir.

\subsection{Dizi B: Çapraz Donatı ile Güçlendirme Deneyleri}

- Gerekli miktarda çapraz donatılar birleşim bölgesine yerleştirilir ve uçları uygun şekilde ankrajlanırsa performansın arttığı gözlenmiştir.

- Birleşim bölgesini çapraz donatılarla güçlendirmede (S20B \& S20W) somunlu ya da kaynaklı olarak donatı uçlarını ankrajlama oldukça başarılı sonuçlar vermiştir. Fakat S20 deneyindeki gibi uçları ankrajlamadan, donatıları birleşim bölgesinden geçirmek yeterli olmamıştır.

- Çelik donatılarla yapılan güçlendirme çalışmalarında nervürlü donatıların miktarı önemlidir. S20B \& S20W deneylerinde bir yöndeki çapraz donatılar, yönetmelik gereği olan birleşim donatısının (etriye) üç katı kadar uygulandığında oldukça başarılı sonuçlar elde edilmiştir. S16B \& S16BL deneylerinde ise birleşim bölgesindeki donatı miktarının 1/3 oranında azalmasıyla kapasitede de 1/3 oranında azalma meydana gelmiştir.

- Çapraz donatıların bindirmeli olarak birleşim bölgesinden geçirilmesiyle oldukça başarılı sonuçlar elde edilmiştir. Bindirmeli olarak uygulanan S20BL ve S16BL deney elemanları S20B ve S16B deney elemanlarıla hemen hemen aynı sonuçları vermiştir. 


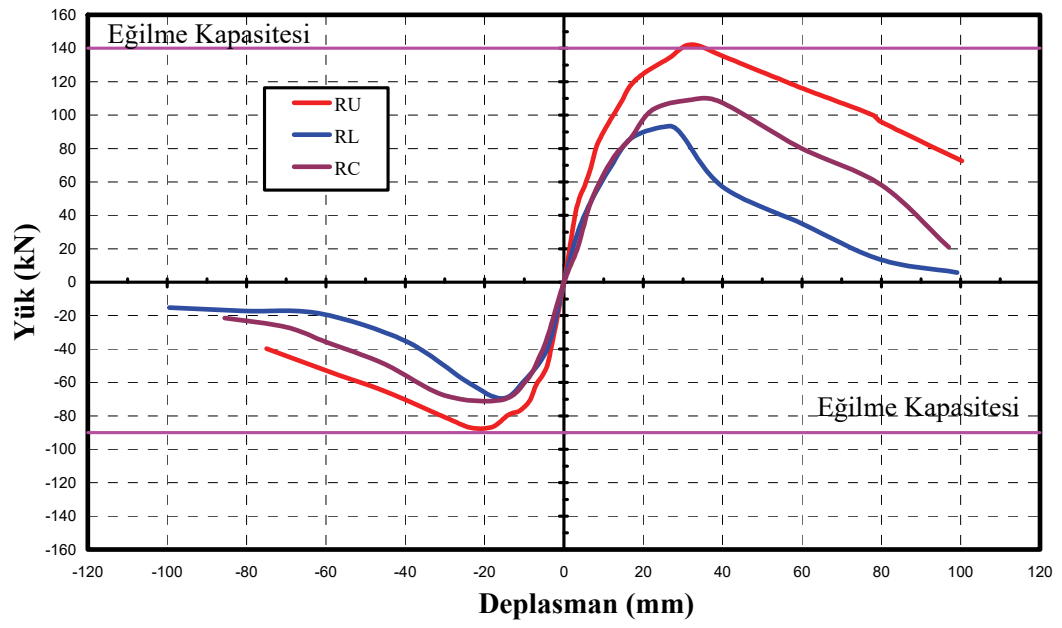

Sekil 9. Referans deney elemanları (Dizi A)

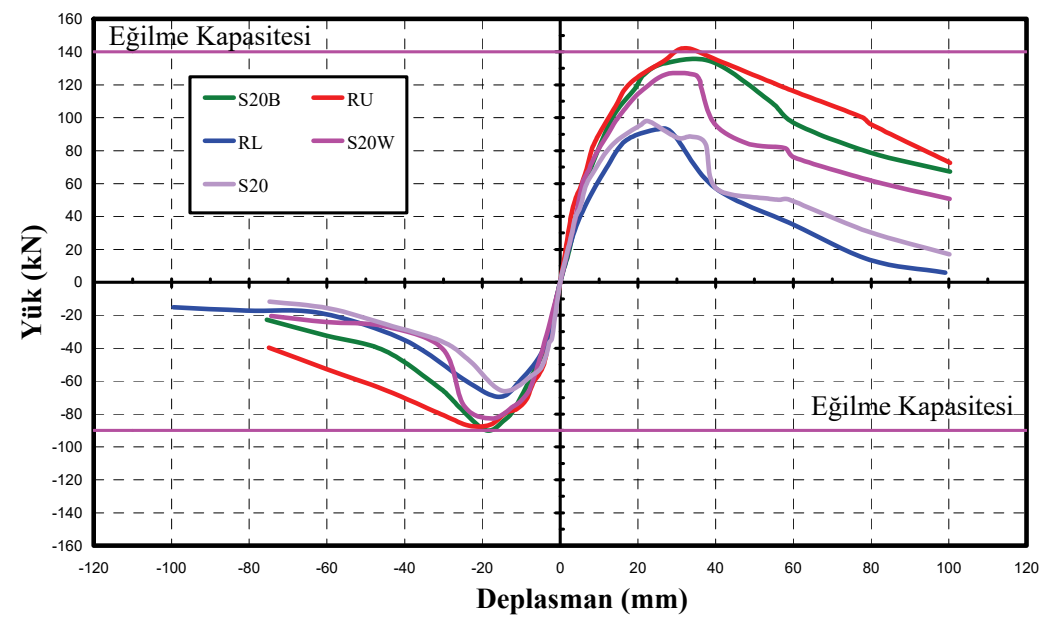

Şekil 10a. Çapraz donatı güçlendirme deneylerine ait zarf eğrileri 


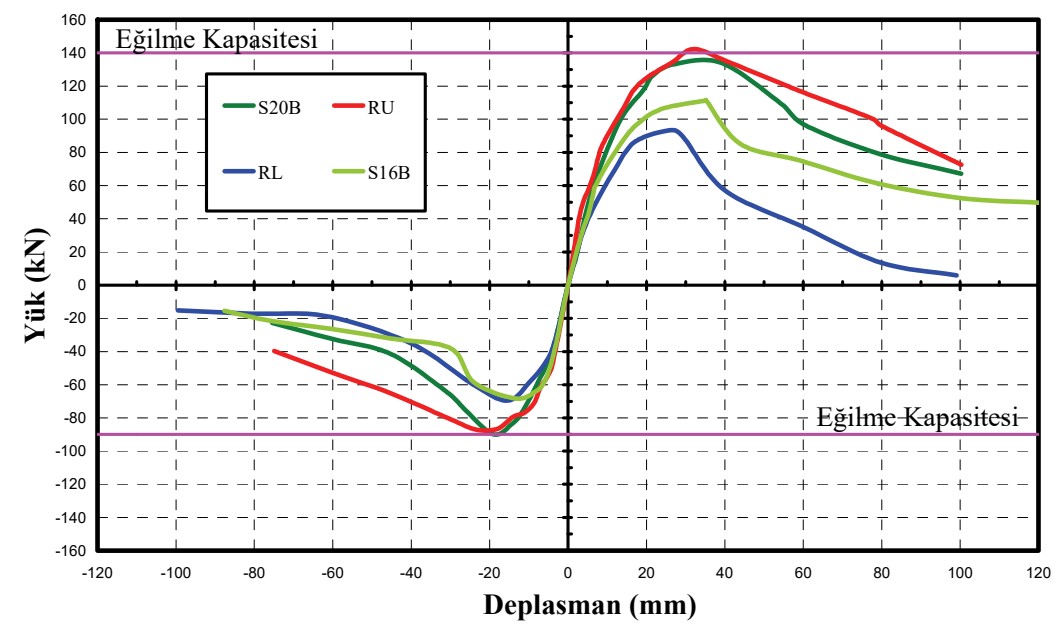

Şekil 10b. Çapraz donatı miktarına bă̆lı güçlendirme deneylerine ait zarf ĕgrileri

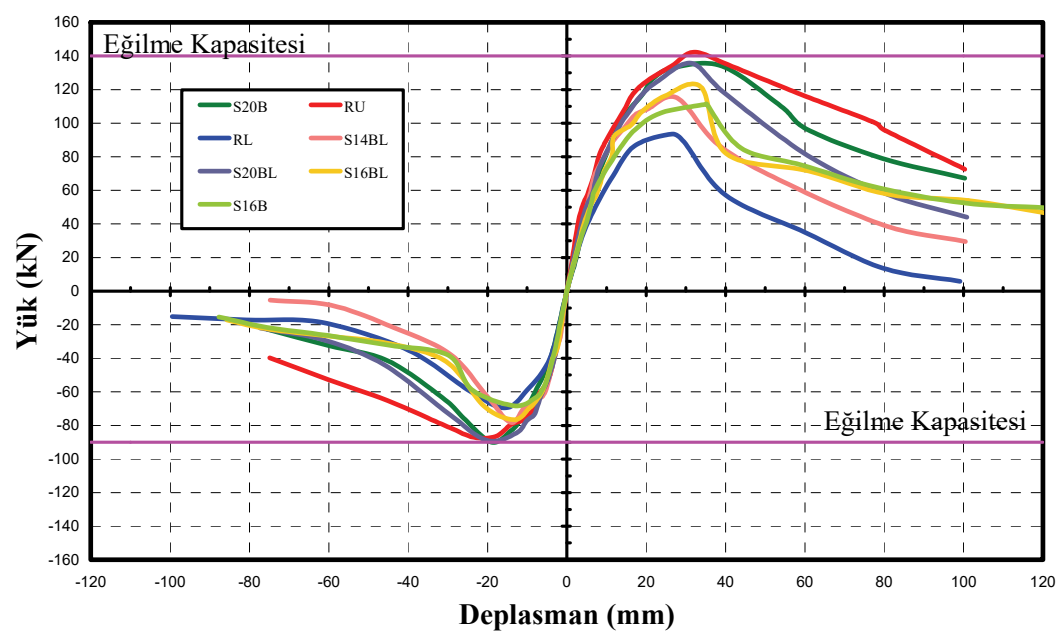

Şekil 10c. Bindirmeli donatı güçlendirme deneylerine ait zarf ĕgrileri

Şekil 10. Çapraz donatı ile güçlendirme deneyleri (Dizi B)

\section{SONUÇLAR VE UYGULAMA ICÇIN ÖNERILER}

Tipik bir betonarme yapının dış birleşim bölgesini gösteren, 2/3 ölçekli onbir deney elemanı üzerinde yapılan birleşim bölgesi güçlendirme çalışmalarından etkili ve başarılı olarak elde edilen sonuçlar aşağıda belirtilmiştir. 


\subsection{Sonuçlar}

- Yönetmeliğin öngördüğünden \% 25 daha fazla birleşim donatısı (RC), kirişin akmasına ulaşmayı sağlayamamıştır. Yönetmelik donatısının iki katı kadar etriye konulduğunda, kiriş donatısının akma konumuna gelmesi ancak sağlanabilmiştir; kirişte mafsallaşmabirleşimde ezilme türü bir bileşik kırılma elde edilebilmiştir. Bu gözlem yönetmelikte öngörülen birleşim donatısının bazı durumlarda yetersiz kaldığını göstermesi bakımından çok önemlidir. Ancak, deney elemanının en elverişsiz durumları yansıttığı, kuşatılmamış birleşim olduğu ve yüksek kesme kuvvetine maruz kaldığı anımsanırsa, bu yetersizliği, kesin bir yargıya dönüştürmek doğru değildir. Bu sonucun, yönetmelik yapanlar tarafından dikkate alınmasının uygun olacağı düşünülmektedir.

- Birleşim bölgesi güçlendirilmesi için önerilen bu teknik oldukça etkili ve pratiktir. Çapraz olarak iki yönde yerleştirilen nervürlü donatıların, kesme donatısı olarak performansı arttırdığı gözlenmiştir. Ancak, sargılama etkisi olmadığından, birleşim bölgesine yerleştirilen etriyelerin yerini tutamayacağı gözönünde bulundurulmalıdır.

- Önerilen teknikte kiriş-kolon birleşim bölgesini güçlendirmede çelik donatılar etkili bir biçimde kullanılabilir.

- Çelik donatılar uygun şekilde uçlarından ankrajlanmalıdır.

- Bindirmeli çapraz çelik donatılarla yapılan güçlendirme çalışmalarından, iki ucundan kenetlenmiş çapraz donatıyla yapılan güçlendirmelere eşdeğer sonuçlar alınmıştır.

- Deney elemanı, "yanal ötelenmesi önlenmiş" bir çerçeveden çıkarılmıştır. Bu çalışma öncü bir çalışmadır. Ayrıca ileride yapılacak olan "yanal ötelenmesi önlenmemiş" çerçeve davranışını içeren daha karmaşık deney düzeneklerinin kurulmasında yararlı olacağı düşünülmektedir.

- Tabla donatısının katkısıyla, kirişin eğilme kapasitesi yükseleceğinden, kirişte mafsallaşma zorlaşacak, birleşim bölgesi dayanımının daha da yüksek olması gerekecektir. Ancak, yukarıda da belirtildiği gibi bu bir öncü çalışmadır. Bu deneylerin ileride yapılacak tablalı eleman deney çalışmalarına katkı sağlayacağı amaçlanmıştır.

\subsection{Uygulama İçin Öneriler}

- Betonarme yapıların güçlendirilmesinde iki çeşit uygulama vardır. (i) Eleman Güçlendirme Teknikleri, yapılarda çerçeve elemanlarının deprem davranışı açısından bireysel olarak güçlendirilmesi ve (ii) Sistem Davranışı İyileştirme Teknikleri uygulamalarındaki amaç ise, mevcut yanal yük taşıyıcı sisteme aktarılan deprem etkilerini azaltmaktır. Bunun için ya deprem yüklerinin büyük bölümünü alarak mevcut yapıyı rahatlatan, yeni elemanlar yerleştirilir ya da taban yalıtımı sistemleri ve sönümlendiriciler kullanılarak deprem etkilerinin yapıya aktarılması engellenmeye çalışılır. Önerilen teknik elemanların bireysel olarak güçlendirilmesiyle yapılan ilk gruba girmektedir.

- Mevcut birçok yapının depreme karşı güçlendirilmesi gerekmektedir. Kiriş-kolon birleşim bölgelerinin çelik donatılar ile güçlendirilmesinde, önerilen tekniklerden oldukça başarılı sonuçlar elde edildiğinden, bu teknikler güçlendirme çalışmalarında uygulanabilir. 
Kiriş-Kolon Birleşim Bölgesinin Depreme Karşı Çelik Donatılarla Güçlendirilmesi

- Çelik donatılarla yapılan güçlendirme çalışmalarında uygulama kolaylı̆̆ı açısından daha az sayıda, büyük çapta nervürlü donatıların kullanılması tercih edilmelidir. Genel kural olarak bir yöndeki çapraz donatıların çekme kapasitesi (donatı alanıyla çeliğin akma dayanımının çarpımı), yönetmelik gereği olan birleşim donatısının eğik doğrultudaki çekme kapasitesinin üç katına eşdeğer olmalıdır (birleşim bölgesindeki etriye sayısı, her etriyenin iki kolu, etriye alanı, etriyenin akma dayanımı ve yaklaşık olarak Cos $45^{\circ}$ kabul edilerek 0.7 ile çarpımının üç katı kadar).

- Güçlendirilecek birleşim bölgesinin geometrik çizimi ve incelenmesi yapılmalıdır. Bölgede mevcut olan donatıların yerleri dedektörlerle belirlenerek çizimde işaretlenmelidir.

- Bazı birleşim bölgelerinde mevcut olan yoğun çelik donatılar nedeniyle bir köşeden diğer köşeye matkap ile tek doğrultuda delmenin yapılamaması durumunda; karşılıklı köşelerden iki paralel delik açılarak, çelik donatılar yerlerine bindirmeli olarak yerleştirilmelidir.

- Çelik donatılarla güçlendirme çalışmalarında, uçlardan ankrajlamayı somunlu veya kaynaklı olarak yapmak için bazı profil ya da plakalar gerekmektedir. Bu parçaların uygulamadan önce hazırlanmasına gereksinim duyulmaktadır.

- Hazırlıklar tamamlandığı zaman çelik donatılar, beton içinde önceden açılmış olan deliklere yerleştirilmeden önce boşluğun içine epoksi enjekte edilmelidir. Epoksili boşluğun içine, epoksi sürülmüş çelik donatılar yavaş yavaş döndürülerek yerleştirilmelidir. Somunla yapılan güçlendirmede, dışarıda kalan diş açılmış donatı uçları, somunlar yavaş̧̧a sıkılmak suretiyle plakalara tutturulmalıdır. Kaynaklı ankraj işleminde ise; epoksiyi yakmamak için kaynak yapılırken devamlı su ile soğutma yapılmalıdır.

\section{Kaynaklar}

[1] Antonopoulos, C. P., Triantafillou, T. C., Exp Investigation of FRP Strengthened RC Beam-Column Joints, Journal of Composites for Construction, 344(7), 39-49, 2003.

[2] Ghobarah, A., Said, A., Seismic Rehabilitation of Beam-Column Joints Using FRP Laminates, Journal of Earthquake Engineering, 5(1), 113-129, 2001.

[3] Prota, A., Nanni, A., Manfredi, G., Cosenza, E., Selective Upgrade of Under-designed RC Beam-Column Joints Using CFRP, ACI Structural Journal, 101(11), 699-707, 2004.

[4] Taşlıgedik, A.Ş., Lap Splice Behaviour of CFRP Rolls, Yüksek Lisans Tezi, Orta Doğu Teknik Üniversitesi, Ankara, 2008.

[5] Gökdemir, H., Kiriş-Kolon Birleşimlerinin Depreme Karşı Güçlendirilmesi, Doktora Tezi, Eskişehir Osmangazi Üniversitesi, Fen Bilimleri Enstitüsü, İnşaat Mühendisliği Anabilim Dalı, Eskişehir, 2009.

[6] Seçkin, M., Hysteretic Behaviour of Cast-in-Place Exterior Beam-Column SubAssemblies, Doktora Tezi, Toronto Üniversitesi, Toronto, Kanada, 1981. 